
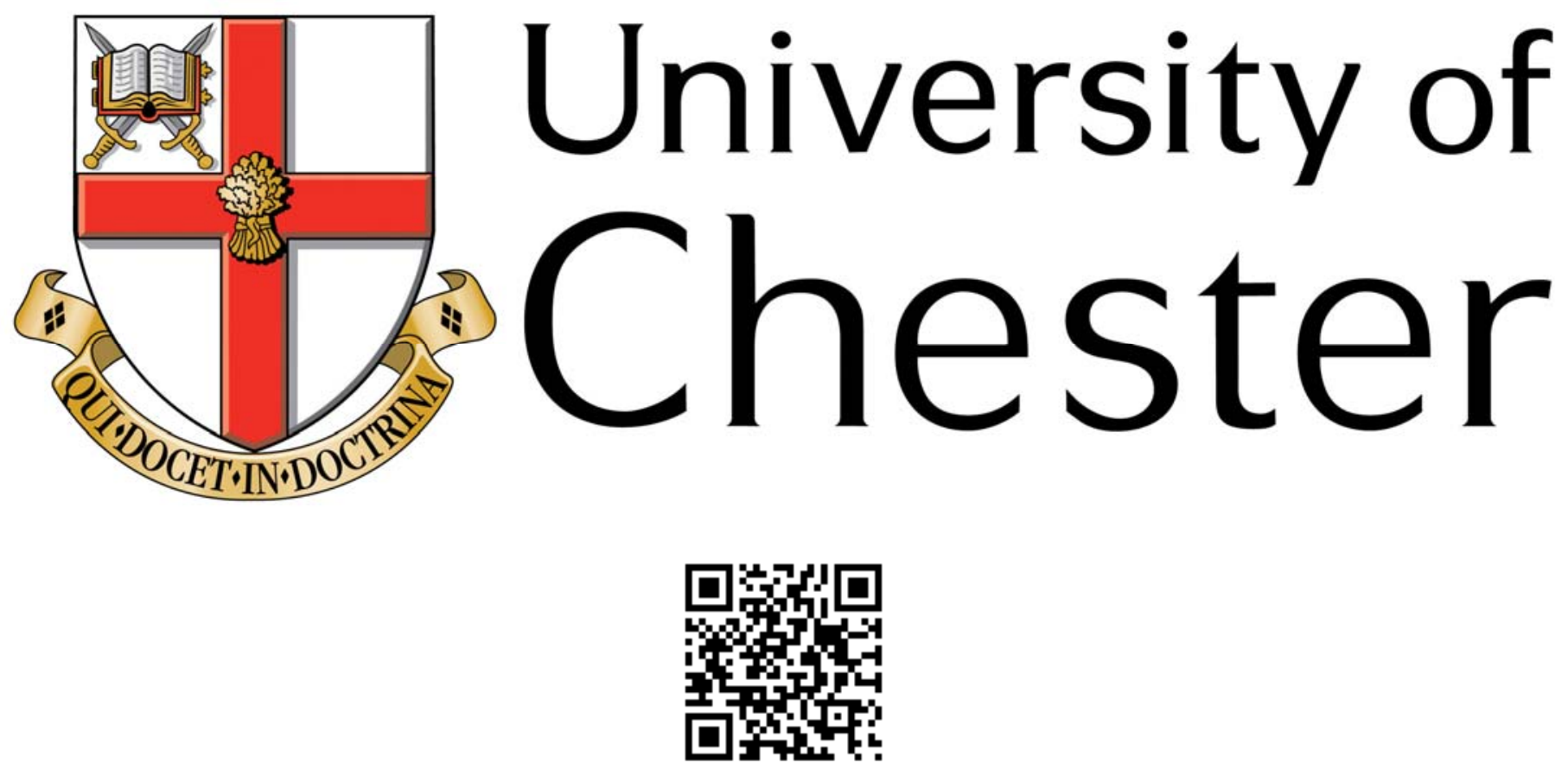

This work has been submitted to ChesterRep - the University of Chester's online research repository

\title{
http://chesterrep.openrepository.com
}

Author(s): Valentina Cuzzocrea ; Rebecca Collins

Title: Collaborative individualization? Peer-to-peer action in youth transitions

Date: May 2015

Originally published in: Young

Example citation: Cuzzocrea, V., \& Collins, R. (2015). Collaborative individualization? Peer-to-peer action in youth transitions. Young, 23(2), 136-153. http://dx.doi.org/10.1177/1103308815569390

Version of item: Authors' post-print

Available at: http://hdl.handle.net/10034/347043 


\section{Collaborative Individualization? Peer-to-peer action in youth transitions}

\section{Introduction}

In this article, we propose an iteration of the concept of individualization which describes how some young people, faced with significant economic uncertainties, concurrently sow the seeds of more equitable and resilient socio-economic systems, and do so specifically through collaboration among peers. We describe this in terms of collaborative individualization (henceforth, C.I.) and offer our reflections as a first conceptual step in the direction of a more analytical approach to the forms of collaboration young people enact.

Ulrich Beck, in Individualization, argues that 'new orientations towards the 'we' create something like a co-operative or altruistic individualism' (2002:162). Collaborative tendencies in individualised contexts have thus been acknowledged in existing literature (see also Bauman 2001). In contrast, popular notions such as that of 'networked individualism' (Castells 1996) suggest that social relations are shaped on the basis of individual values and interests, more than an overriding desire to be 'networked' in a collaborative sense. Most commonly, however, research has depicted peer collaboration in terms of aspiration or proposition, rather than as an observed reality on which it is possible to reflect.

To introduce the relevance of an alternative framing of individualization which seeks to analytically embed forms of collaboration, we begin by quoting a blog post in which Lina, a participant in the case study project we discuss here, counterposes economic instability in Greece with one way in which some young Athenians have contested the associated narrative of "despair":

"In the current economic circumstances in which despair reigns supreme and the youth faces social exclusion and a fast-rising unemployment rate, the Athens Travelers program creates an opening for the youths' innovative force. It aims to bring together young people from different educational, social and cultural backgrounds and the young with fewer opportunities [...] to nourish mutual understanding, support and cooperation.” 
Lina conveys that, despite facing the most challenging socio-economic context in decades, some young people are refusing to accept their labelling as a "lost generation" and are instead creating new ways of being productive. Most significantly, in this quote a proactive search for collaboration appears fundamental to these efforts. In one sense this might not be surprising; at times of crisis the driving force behind the generation of a social movement is the search for like-minded others in pursuit of a shared goal (Della Porta and Diani 2009). Yet recent theorisations of young people's transitions to adulthood and their construction of their biographies and life trajectories have largely remained allied with a 'sole traveller' characterisation suggested by the individualization thesis (Beck and BeckGernsheim 2002) seemingly condemning individuals to isolation or loneliness.

This article aims to add nuance to the individualization thesis by reflecting on its applicability to the lived realities of European youth. We do not seek to fundamentally challenge the thesis itself; there is much that holds true in the context of young people's attempts to manage the specific 'risk society' (Beck 1992) constituted by receding welfare provision and macro-economic uncertainty. Indeed, in the current context young people are particularly exposed to the 'precarity' associated with changing socio-economic patterns and structures in Europe (Waite 2009). We begin with a brief overview of recent engagement with the individualization thesis in the context of youth transitions to adulthood located in the Global North ${ }^{2}$. This is followed by an introduction to Edgeryders ${ }^{3}$, the project which has informed this paper, which was concerned with understanding how European youth address the challenges associated with achieving independent adulthood. We then present a series of work areas drawn from the project which substantiate our proposed iteration of the individualization thesis. These demonstrate collaboration at work in participants' attempts to create opportunities, and thus reveal C.I. in practice, explicating its meaning and implications.

\footnotetext{
${ }^{1}$ All participants' names are reported as displayed on the Edgeryders platform; some used pseudonyms, some others their actual names.

${ }^{2}$ We explicitly acknowledge the location of both the project discussed and the associated kind(s) of youth transitions in the Global North, where the transition from childhood to adulthood tends to be characterised by growing independence from adults. This is in contrast to child-to-adulthood transitions in the Global South, which have been described as characterised by growing interdependencies, with young people becoming less rather than more independent with age (e.g. Langevang and Gough 2009; Simone 2005). A more detailed discussion of this distinction is outside the scope of this paper.

${ }^{3}$ The project has been funded by the European Commission (Directorate of General Employment and Social Cohesion) and the Council of Europe, and developed by Social Cohesion Research and Early Warning Division of the latter).
} 


\section{Youth Transitions and Individualization}

There is growing acknowledgement that the notion of 'transition' - used to describe the process of change and adjustment between youth and adulthood - is no longer an unproblematic description for the events that characterise this phase of the life course. Research has described the dissolution of traditional, well-worn, linear pathways to a particular anticipated form of adult life; fewer, less predictable, or more precarious, life prospects; a new set of challenges characteristic of the contemporary, globalized world; and more fluid, volatile processes and procedures as the only tools available for its navigation. Thus, even whilst there remains debate concerning the terminology used to theorise how these events are understood and responded to, the importance of this process of change and adjustment in young people's lives is in no way diminished. Debates about the risks that characterise the transition from youth to adulthood have been somewhat dominated in the last two decades by the individualization thesis, as elaborated by Beck (1992), Beck and Beck-Gernsheim (2002), and further discussed by others (e.g. Bauman 2001; Biggart and Walther 2005; Côté 2002). Recent scholarly debate has sought to reconstruct the significance of some of Beck's theory for youth studies (Roberts 2010, 2012; Woodman 2009, 2011), in some cases forging revealing parallels between the precarity of youth employment opportunities in developed economies and the longstanding insecurity and informality which characterises labour markets in the Global South (e.g. Furlong and Kelly 2005). Here, we focus on those aspects of the individualization thesis which underscore the challenges for young people in realising their transition to adulthood.

2.1. Institutional individualization. Individualization is primarily concerned with the lack of linearity which characterises the progression of everyday life in 'late' or 'reflexive' modernity. Fundamental to this is the transformation of human identity into a perpetual task requiring ongoing maintenance and refinement. Individuals are charged with the responsibility of performing that task, and for managing the consequences of that performance. Most significantly, in the context of a 'risk society' in which social and institutional structures are argued to be falling away, individuals are required to make decisions freed from the 'guiding hand' of traditional obligations. Beck argues that in such situations everyday life becomes a reactionary project in which 'individualized individuals' live for the moment and must find 'biographic solutions to systemic 
contradictions' (1992: 137). At the heart of these contradictions lies the fact that, whilst on the one hand the individualization thesis argues for the decreasing relevance of classical sociological categories such as class and family position, on the other, the individualization process itself becomes institutionalized as acceptance of the individual as the core social unit becomes normalized. This is manifested most vividly in the increasingly ubiquitous construction of individuals as 'consumers' of a wide range of services, opportunities and experiences. In the contemporary era it is these new constraints and dependencies - based on our capacity to choose, act on those choices and manage their consequences - that must be negotiated (Pollock 2002; Leccardi and Ruspini 2005; Schwartz et al. 2005).

Whilst the argument perceived in the individualization thesis for the decreasing relevance of class and family position has faced significant critique due to lack of empirical substantiation, as well as direct empirically-informed contestation (e.g. Skelton 2005; Walker 2009), the institutionalization of individualization has instead received some support. Wyn and Woodman (2006), for instance, reporting on young Australians' transitions to adulthood, note how neoliberal state policies, which have embraced the idea of the individualized individual, have produced places for youth in society described by the authors as 'inflexible' and 'exclusionary' (p511), far from the imagined model of reflexive choice and freedom (see also Kelly 2000). This echoes the conclusions of Evans (2002), whose study of young Brits' and young Germans' transitions into the labour market demonstrated that young people were acutely aware of the limitations imposed on their abilities to make 'individualized' choices about their futures by the social structuring of their environments. This was in spite of her participants' strong belief in meritocracy based on individual achievement.

The sphere of life in which the institutionalization of individualization is most vividly, yet also oppressively, manifested for many young people is that of work. Focusing on work through the lens of individualization, it becomes a particularly crucial reference point for young people's identity formation (Best 2011) as they transition into the domain of adulthood with its associated expectations and responsibilities. If identity is a 'project' (Giddens 1991) necessitating ongoing choice-making in pursuit of personal goals, then fundamental to that project's success is the appropriation of meanings associated with what an individual is able to contribute to society through their labour. Walker (2009) has highlighted how loaded this 'choice project' is in his case study of working class Russian youth. These young men's most profound experience of individualization has been 'the 
individualized attribution of blame for 'wrong choices'” (p531) - despite the only 'career' choices available to them being equally unviable ‘transitions to nowhere’ (p532).

2.2 Collaboration as an emergent element of institutionalised individualization. Equally important has been the recognition - both by Beck (1992) and others - that individualization need not preclude the existence of some forms of community or collectivism. Bauman (2001) elaborates on this, noting that the 'non-linear individual' has to develop the skill to put together networks, construct alliances and make deals as a means of countering the instability that characterises a 'risky' socio-economic landscape. Webb (2004), for instance, has argued that care and mutual dependence are central coping strategies in reflexive modernity. Aaltonen (2013) evidences this in her recent study of young Finns' attempts to take control of their lives beyond the completion of compulsory education, in which she emphasises the importance of family relationships, peer networks and institutional resources in her participants' navigation of this life stage. Evans’s (2002) participants' belief in meritocracy was founded on the premise that personal networking constitutes a key part of creating one's own success - making their social connections 'work for them' formed a central strand of their individualized approach to their anticipated employment trajectories. The importance of personal networking has been taken up by Chua's (2013) study of 'networked individualism' in Singapore, in which he explores the complexity that characterises the contemporary requirement to balance personal autonomy with active networking in order to forge and maintain the 'right' connections.

Thus, even when youth transitions to adulthood are characterised by very different forms of (in)flexibility, impacted to a greater or lesser extent by an individual's family background, or shaped by contrasting socio-economic contexts, extant research has noted that what links youth transitions across these differences is young people's ability - and apparent desire - to simultaneously fulfil their individual needs and connect with a diverse range of external social entities (our emphasis, Walther 2006; also Jones et al. 2006). These studies already go some way to demonstrating young people's possession of sometimes significant capacity to resist the demands or obligations imposed by institutional power structures, with youthful manifestations of agency growing in number, scale, diversity and the complexity of their inter-connections. Although recent empirical work has suggested young people's relationships with formal institutional structures to be largely ambivalent, other types of relationships come to the fore which emphasise the 
necessity of collectivism in some form within the transition process. At times of socioeconomic and political upheaval, this collectivism is often forged amongst young people themselves, as in Nugin's study of young people's life-planning in post-socialist Estonia (2013), at least in part as a mutually beneficial support structure. As has become increasingly conspicuous across Europe since the onset of the global recession in 2008, young people have applied themselves to enacting new, often innovative forms of mutually-supporting collaboration as a coping strategy.

In sum, youth are facing the sharp end of the contemporary socio-economic crisis. Their struggles are exacerbated by policy frameworks which have institutionalized individualized youth, simultaneously constraining the choices from amongst which they exhort young people to choose. It is in this context that the project on which we report here was situated. Based on our analysis of the qualitative project data, we propose the notion of collaborative individualization (C.I.) as a means of characterizing young people's attempts to define their identities as simultaneously self-reliant and in need of support and collaboration.

C.I. reflects the diversity of potential future pathways and lifestyles open to young people; recognises, but does not demand, the frequent overlap or intersection of these (experimental) pathways or lifestyles amongst those attempting them; and acknowledges the transience of these intersections, which may only last for as long as all parties involved benefit from the alliance. Such temporary collective associations echo Bennett's framing of 'neo-tribes' (1999), although C.I.'s focus extends beyond a youth cultural project to a broader set of socio-economic experiences, livelihoods and lifestyles. C.I. also emphasises the necessity of commitment to innovative, sometimes unorthodox, solutions to the socioeconomic crisis and its impacts, as well as trust amongst those producing, delivering and benefitting from those solutions - i.e. not only young people; equally wider communities, as well as the public and private institutions who may be (at least partially) absolved of the responsibility of providing their own solutions. C.I. aims to complement the idea of networked individualism by acknowledging the complex spatial distribution of young people's support structures, whilst highlighting the presence of communitarian aspirations absent from Chua's (2013) framing. C.I. also seeks to work with the notion of institutionalized individualization by taking it in two directions: firstly, by problematizing this facet of the individualized society as a structure C.I. seeks to negotiate, even subvert; and secondly, by framing it as an entity with which the collaboratively individualized 
might productively engage. We move now to a brief outline of the project, where we describe its main aims and the methodology employed.

\section{The case study: Edgeryders}

Edgeryders was a project convened by the Council of Europe and funded largely by the European Commission. In the policy terms in which it was conceived ${ }^{4}$, its primary aim was to explore where (both geographically, and in the sense of in which policy areas) existing national and transnational youth policies were failing to provide adequate support structures and mechanisms for young people's transitions from dependent youth to independent adulthood ${ }^{5}$. The project was conceived as an open and flexible exercise and designed to elicit spontaneous, bottom-up contributions from participants. In this way an arena was constructed within which participants could offer mutual support in their attempts to construct viable livelihoods in the midst of extreme socio-economic volatility. Both the participants' contributions - and our analyses of them - have been produced and responded to in the context of a neo-liberal policy environment; in short, the participants knew they had to 'play the game' imposed by the Council of Europe in order to push their voices into the policy domain and have them accorded credibility. That this was so does not undermine the points they raised or the experiences that were shared. Furthermore, regardless of the extent to which Edgeryders might have reflected an attempted panacea for the lack of meaningful support provided by the wider policy community, the project facilitated the forging of relationships between participants in ways which also offered valuable insight into what these young people felt had been lacking in terms of institutional support, as well as some of the ways in which they were going about filling these gaps independently.

Developed and managed by a small project team based at the Council of Europe in Strasbourg, the data collection mechanism took the form of an online 'platform'. Potential research participants were sought through online and offline social networks by a group of 'engagement managers', and were invited to join the project by signing up through the

\footnotetext{
${ }^{4}$ Gilda Farrell, Head of the Division, states: 'we hope that we have contributed to the debate on the purpose of policies to facilitate transitions and inclusion in response to growing insecurity' (volume edited by author 2 , page 8 , details removed).

${ }^{5}$ The main results of the Edgeryders project are presented in a volume edited by AUTHOR 2 (DETAILS REMOVED). The name Edgeryders expresses the idea that some young people are already enacting innovative projects and lifestyles, and that therefore they can be part of the solution rather than merely a social problem (AUTHOR 2,page 9).
} 
website to join the online Edgeryders community. Once inside the platform, participants were presented with a series of topical themes - such as employment, education, political participation, access to commons, and social relationships - which were described in the platform as 'Campaigns'. Within each 'Campaign' was a series of 'Mission Reports' provocative questions, quotes or statements, to which participants were invited to respond in the form of a blog-style mini article. It was these 'posts' that comprised the project data. Our analysis is based primarily on these texts but also makes reference to some activities generated by participants' interactions within the project.

The project platform was ‘live’ from October 2011 to June 2012. During that time over 900 users registered, with around 200 of those becoming regular contributors ${ }^{7}$. Participants reached the platform following interaction with an 'engagement manager', on the basis of a recommendation from a friend or acquaintance ${ }^{8}$, or opportunistically whilst browsing the web. Their interactions within it were wholly self-selecting, with participants opting in and out as they chose: some engaged regularly throughout the full duration of the project; others participated intermittently, infrequently or only once. Participation was on a purely voluntary basis. Participants were most commonly based in France, Italy or the UK (reflecting the social networks of much of the core project team), but there were also large numbers of participants from Spain, Germany, Sweden, Belgium and Romania, as well as the US and Canada. It was agreed that perspectives from beyond Europe were welcome contributions, since the socio-economic issues at the heart of Edgeryders were occurring elsewhere in the world ${ }^{9}$.

The ratio of male to female participants was approximately 2:1. Although participants were not required to divulge their age in order to participate, some did so in the course of their posts. For those who did not, it was evident from the experiences relayed (such as common references to studying at university currently or recently) that the vast majority were between the ages of 20-35. Similarly, through the biographical details shared by participants in the course of their Mission Reports, it was clear that most were university educated, with some holding one or more postgraduate or professional qualifications.

\footnotetext{
6 These 'Mission Reports' can be viewed in the project archive, hosted by the new Edgeryders website (requires signing up to a free log-in): http://edgeryders.eu

${ }^{7}$ For a discussion of the community's characteristics and the general issues discussed, see AUTHORS, 2013 (DETAILS REMOVED).

${ }^{8}$ This was actively encouraged by the project team and engagement managers in order to increase the flow of potential participants to the platform.

${ }^{9}$ A network analysis is available (Marcus and Vickers 2012)
} 
Thus, whilst in some respects the sample was very diverse, it was recognised that some voices were not well represented, particularly young people who remain excluded from online space for reasons of politics or poverty. This was acknowledged as an important future area of work for the project team, but not one that it was possible to accommodate within this project. Nevertheless, the breadth of experience that characterised the overall project sample was able to provide some valuable insights into the specific challenges and frustrations of contemporary European youth as they navigate the transition to independent adulthood.

The data produced in this project was qualitative, taking the form of the Mission Report texts (i.e. the participants' blog posts) and the 'comments' on each post added by other participants. The style and length of each post varied significantly (from around 200 words to over 2000 in some cases), with some written as conversational expressions of experience or opinion, and others more akin to a formal article. The comments stream which followed each post consisted of generally short ( $<50$ word), conversational responses in the form of questions, ideas or shared views or experiences. The analysis of these texts was conducted using WEFT QDA, an open source qualitative analysis software. The textual data was open coded, with the selection of codes led wholly by the data itself, following a grounded theoretical approach (Charmaz 2006; Corbin and Strauss 1990). Code groups were compared and combined in order to inform a more theoretical analysis. This was led equally by a sensitivity to the relevance of the individualization thesis to this topic and the emergent key themes from the first round of analysis, which highlighted multiple forms of collaboration. In section four, we present a series of examples of the project participants' collaborative tendencies before discussing how these, alongside similar examples, formed the basis of our framing of C.I.

\section{Collaborative individualization in practice}

We move now to a discussion of some of the issues raised and responses articulated by Edgeryders participants. These are presented as a series of work areas through which we aim to reveal some of the ways in which participants' actions express our proposed notion of C.I. The first work area (i) illustrates something of the lived realities described in participants' blog posts. It reports the experience of two Edgeryders participants as they shared it with others. The activities reported took place before the advent of the platform, 
but fed into the platform discussions. The second (ii) explores how an Edgeryders conference made evident a coherent connection between online comments and actual behaviour. The event was organised by the management, but again it served as a locus for the discussions of the participants, and it is therefore directly linked to the blog posts analysed. It is then further elaborated in two of the outcomes of the Edgeryders project: a formal letter collaboratively developed in the online platform space addressed to policymakers (iii); and the constitution of a social innovation space, the 'UnMonastery', located in a disused monastery and former call centre in Matera, Southern Italy (iv). Both these examples originate from the discussions taking place in the platform and then exemplify the output of collaborative work. The first is primarily addressed to policy makers, while the second to the wider community of fellow Edgeryders and Materani. The latter example, although reporting activities beyond the platform, is a direct output of the online discussions and, as such, relevant for our theorisation of C.I. All the discussed work areas have been selected from a variety of examples of participants' collaborations because they span a diverse range of activities within which we identified C.I. at work. They are significant, although not representative, examples of C.I. as it emerged from different Edgeryders' activities reported in the platform.

\section{i. Reclaiming Spaces, Recovering Commons}

Despite the online nature of Edgeryders' communication, participants' attempts to attain independent adulthood through the pursuit of concomitantly individual and collective aims was directly connected with, and situated in, a specific geographical locale. These individuals had either sought out or collaboratively created initiatives which allowed them to express the importance of place and culture in their personal life projects. These initiatives were more than a vehicle for the navigation of young people's transitional life phases. They also offered local communities the means to reclaim public spaces from institutional powers for community benefit, whilst simultaneously creating a forum in which related local socio-economic problems could be discussed. This was made evident in several Mission Reports, in which participants described initiatives in which they were involved.

Lina brought to the platform her experience of two initiatives in which she participated in Greece: 'Athens Travelers' and 'Polypolis', devised by young members of the non- 
profit organisation SARCHA (School of Architecture for All) as a productive outlet for frustrated, un(der)employed or otherwise precariously situated Greek youth. 'Athens Travelers' uses young Athenians' experiences of the city to create "alternative” guided tours. With the project website stating, "[I]ndividual trajectories are turned into 'in common' city explorations”10, the aim is to 'map' Athens through young people's eyes, reframing a city associated with the worst impacts of economic instability through the potentialities that characterise young Athenians' aspirations for a more resilient future. Seeking to engage young people from all socio-economic and cultural backgrounds, 'Athens Travelers' represents a practical manifestation of youth solidarity in a context in which participants bring their personal experiences of Greece's present challenges to bear on devising both individual and collective ways forward. 'Polypolis' is similarly concerned with tackling Greece's socio-economic challenges by bringing young people's creative thinking to bear on urban planning issues. 'Polypolis' is a role-playing social game in which young participants adopt different roles typical of urban planning negotiations (landowner, shop owner, investor, resident, etc.) before debating the optimum design and resource allocation for a designated city block. Like 'Athens Travelers', it seeks to mobilise young people's passions in order to generate ideas and action for more resilient cities, forms of urban social life and economic prosperity.

A series of Mission Reports produced by another participant, Alessia Zabatino, highlight how the C.I. suggested by the above accounts constitutes a practical means of (re)creating communities who are aware of the limits, challenges and potentialities of the place in which they are situated, yet who work constructively with them for community benefit. Alessia's reports dealt with the occupation of cultural buildings across Italy and represented a somewhat different approach to mobilising the passions of the young precariat, although one which retained at its heart the desire to fulfil individual aims in a context of collectivity. Reporting on the 'reclaiming' of historical theatres and cinemas from disuse precipitated by institutional neglect or corruption, she described them as "places where we take care of [our] own cities and citizens, places where [we] implement new social policies based on co-operation and the identification of real urgencies." With participation of local residents strongest in working class neighbourhoods, each site had evolved to provide what was needed by its local community. This included: childcare provision; a barter marketplace; a location for seminars, lecture and workshops; business

\footnotetext{
${ }^{10}$ http://athenstravelers.wordpress.com/
} 
support and legal guidance; an arts venue; and a social and entertainment space for the elderly. With all activities co-ordinated by volunteers, the occupation of these spaces fulfilled two aims for the occupiers: first, to represent a call for changes to labour laws such that better provision is made for precarious workers; and second, to reclaim historic and culturally significant spaces for public use and benefit. Here, at the same time as collaboratively managing the provision of spaces and services for vulnerable or otherwise precarious social groups, the young occupiers simultaneously produced a context in which they could fulfil individual needs, including the development of professional skills (such as negotiating with institutions), networking, and living and working according to personal principles.

What these examples demonstrate is that, for some young people, the anxiety stemming from their personal precarity is being channelled into actions which both involve and impact upon people beyond themselves. Lina and Alessia Zabatino - as representative of many of their fellow Edgeryders - marshalled their existing skills in ways that generated both personal and collective benefits.

\section{ii. Living On The Edge - the Edgeryders conference}

From June $14^{\text {th }}-15^{\text {th }} 2012$ the Edgeryders project team hosted the first 'Living on the Edge' (henceforth, LOTE) conference. Bringing together the project team, research team, policymakers from across Europe, and, most importantly, around 120 Edgeryders participants, the aim of the event was to bring into a physical arena the debates that had been developing in the virtual space of the online platform. We incorporate reference to this conference in building the 'case' for C.I. because of its significant role in allowing participants to directly tackle the policy-led institutionalization of individualization, and, instead bring to the door of policymakers alternative, collaborative strategies for supporting European youth.

At LOTE, Edgeryders participants, policymakers and researchers sat at (literally) the same table on the same physical platform. Speakers from each of these groups were invited to share their experiences, perspectives and frustrations around the disjuncture between current youth policy and the lived realities faced by contemporary European youth. Importantly, rather than confining each speaker to a session where they spoke alongside their direct peers, each section of the conference sought contributions from a combination 
of participants, researchers and policymakers, such that potentially conflicting perspectives on key topics could be articulated and debated openly. This not only gave participants the opportunity to directly challenge policymakers; it equally offered the opportunity for them to present possible solutions, including the collective 'people power' of themselves and their peers as collaborators in helping make those solutions reality 'on the ground'.

Since June 2012 there have been three further LOTE conferences, in Brussels (Belgium, $6^{\text {th }}-9$ th December 2012) and Matera (Italy, $29^{\text {th }}$ October $-3^{\text {rd }}$ November 2013; $23^{\text {rd }}-26^{\text {th }}$ October 2014). These have proved useful stepping stones for the work of what has become a still-growing Edgeryders community, based online and still focused around driving policy change, but equally meeting and working in 'real world' contexts in order to put their ideas into action. This serves to emphasise that the collaborative orientation developed at the level of online discussion persists offline, too. This constitutes an important contribution to the argument we seek to build here. Evidently the quest to devise collaborative solutions to young people's current difficulties is not confined to an online 'talking shop'; rather, online communities of action mirror - or act as a conduit for - their realisation in physical spaces where that action must ultimately be realised.

\section{iii. Letter to Funders}

One of the most immediately concrete outputs from Edgeryders was an open letter from participants to institutional funders of innovation. Collaboratively written both online and through face-to-face discussions at LOTE, and signed by ten named (and many other unnamed) Edgeryders participants, the letter was borne out of frustration that much of the funding for social innovation and business start-ups was inaccessible to younger applicants, either through ineligibility according to funding criteria, or because the applicants possessed neither the experience nor the 'people power' to formulate a successful bid. As one participant, Andrea, noted in a Mission Report, applying for funding can be a full-time job, and it can take time to accumulate enough money to pay for even a part-time fundraiser. Aware that, through the Edgeryders project, they had both the weight of numbers and a degree of political legitimacy granted through the association with the Council of Europe, several participants drafted the letter as a call for a collaborative approach between funders and seekers of funding to improve the processes involved, for 
the benefit of both parties. This intentional mutuality was made clear in the opening page of the letter:

\section{Dear Funders (and other supporters of innovation)}

It's just not working out. The way that you provide support for innovation isn't working for you, or for us. We don't like the bureaucratic processes, high organisational requirements and over-specified funding calls - and we are sure that you don't like administering them either. The financial and social crisis is making reform and agile innovation even more important, but processes are still slow. We'd like to find a better way to get support and resources to innovators who can make change happen, a way that's less bureaucratic but weeds out bad ideas by letting them fail quickly and cheaply. We know it's a bit self-interested, because most of the people who signed this letter are innovators themselves [...] But we think it's in your interests too, because you have complex social goals you want to meet, but you aren't working in ways that create complex solutions. So, we want to have a proper conversation with you about resourcing innovation differently... ${ }^{11}$

In many instances across the project platform, public and private sector institutions were characterised as immutable barriers to the pathways participants aspired to take to independent adulthood; yet this did not always mean that participants sought to completely disengage from them - as this letter demonstrates. Rather, drawing on their individual experiences and personal frustrations, in this instance Edgeryders proposed a solution with the potential to catalyse youth-led innovation across Europe and perhaps beyond.

The conversation which developed in the platform around the construction of the letter led to a crucial development in the Edgeryders story. Discussion about the necessity, in some European countries, of registering an organisation as a legal entity before attempting to partner with organisations or seek funding, opened up thinking amongst both the project team and participants about extending the life of Edgeryders as a community beyond the life of the project. There was sufficient enthusiasm and commitment around making this happen that, at the end of 2012, Edgeryders 'spun out' as a social enterprise. Its main focus since this development has been the UnMonastery. The full version of this is available here: http://edgeryders.eu/help-build-june-
conference/mission_case/funding-20-edgecamp-session-dear-funders-letter 


\section{iv. The UnMonastery}

The UnMonastery is a co-living, co-working community of Edgeryders participants. Located in the historic city of Matera, in southern Italy, at its conception the motivation behind the initiative was described as:

“... to work [...] side by side with the local community on problems that are locally important. The idea is to build groups composed of local and non-local innovators and hackers: the diversity in approaches and experience should lead to new insights and positive breakthroughs."

(BenVickers)

The site of the UnMonastery remains vividly connected to the original monastery's history and culture - both of which resonate with the aims of its present inhabitants - whilst at the same time offering a template for a new kind of social space. As one ‘unMonk' suggests:

"It draws inspiration from 10th century monastic life to encourage radical forms of collaboration and innovation: a sort of lay, off-grid mendicant order striving for a society that can better withstand present and future systemic crises. The key move to achieving this consists in embedding unMonasterians within a local community, and trying to develop a mutually beneficial relationship between that community and the UnMonastery.”

(Andrea Paoletti)

Potential participants in the UnMonastery are invited to apply to spend a three- to sixmonth residency (including free bed, board and working space) working with the core team on a range of projects in collaboration with the local Matera community. The first cohort of 'unMonks' joined the UnMonastery in February 2014 and have worked with the locals to tackle issues including high unemployment, unused housing and commercial building stock, the rolling back of state provision of a range of social services, and the brain drain of young talent to Italy's larger cities, and overseas. It was clear from the start that the motivation behind the UnMonastery was about much more than imitating a corporate-style consultancy project or attempting a radical style of business incubation. Rather, as Ben says, 
"We [...] are motivated by getting the time and peace of mind to work on possible solutions that make sense for a given local context. We do not reject a priori building a good idea into a company, but that might be a future step. We want to start by attacking a problem, not by building a Powerpoint deck with a business pitch."

The UnMonastery presents the opportunity to concentrate on collaboration, for the good of community and for the individuals concerned, with participants freed from the worries of paying rent and earning a salary, whilst they devote their energy to a project in which they can reconcile personal and collective ambitions. Elena sums this up by saying:

"It might sound like something you have heard before millions of times, but what I want is EXCHANGE of skills and ideas!"

The UnMonastery exists within the context of insecurity and precarity in which many young people find themselves trapped, and which is so central to the individualization thesis. At the same time it represents a crucible for the kinds of socio-economic solutions which have been slow to appear at a larger scale. Most importantly, it seeks to mobilise the skills of a diverse range of individuals who are committed to the value of collaboration for driving socio-economic change. It thus constitutes a revealing example of how individual skills and values, harnessed to one another at a grass-roots level, can produce tangible results. We move now to a discussion of the ways in which each of these examples reflects our proposed notion of collaborative individualization.

\section{Reframing Individualization - Collaboratively}

Across the four work areas reported above, a number of recurring themes informed the development of our notion of C.I. First, is the sense that these young people perceive themselves as forgers of their own destiny - they want to be 'full agents', in social theoretical terminology. Importantly, though, these journeys are envisaged as shared with like-minded others in order to ensure support and motivation are close at hand. It was clear that one of the key drivers of many participants' involvement in Edgeryders and its associated projects was the fulfilment of personal needs, often oriented towards their (hoped for) career or livelihood (e.g. the development of particular transferable skills). Yet what at first seemed a wholly individual concern was commonly framed within a wider set of personal values concerned with contributing to a fairer, more equitable, more sustainable and more resilient global society. It should be noted, however, that these 
collaborative groupings of mutual support may not maintain the same form over time - as suggested by the shifting membership of Edgeryders since its inception in 2011. Rather, they may shape-shift as the individuals that comprise them encounter and move through different challenges, and thus affiliate with different communities of support. In this regard Bennett's (1999) discussion of the 'floating membership' of 'neo-tribes' resonates once again, and we see potential here for further work to explore this intersection within youth studies.

A second emergent theme concerned the targets for collaboration. It was evident that local communities were the focus of attention, as participants sought to open up opportunities 'close to home', either literally, in the sense of tackling problems in their home town, or more figuratively, in the sense of creating opportunities for social groups who, like many young people, were experiencing particular precarity. Yet whilst there was widespread commitment to working with 'friends' or 'allies', such as marginalised others or local communities, there was also commitment from some quarters to engaging with 'foes' - business, governments and policymakers. Although these institutions were frequently framed in the Edgeryders project as key conspirators in producing the challenges participants were facing, across the project there was visible commitment to initiating dialogue in order to collaboratively design mutually beneficial ways forward as expressed clearly in the Letter to Funders. The breadth of the collaborative focus, then, was not constrained by participants' frustrations; rather, it was ensured by them, as there was widespread consensus that institutions must be engaged in order to challenge their preoccupation with the excessively individualized individual. In the words of one Edgeryder:

'Many in the community don't trust institutions - deemed as machineries highly resistant to change, limited in their ability to reform - but acknowledge that institutions are made by and of people; and that public servants can build precedents for good practices and cannot be discarded as untrustworthy. [...] The fact that people like Elf or Petros are engaging in conversation through an institutional channel is a good sign that collaboration and mutual support is possible [...].

This is an especially important point to work in the direction of reducing the longstanding issue of youth political disengagement, but it also calls for a more stringent 
interconnection between social theory conceptualization - C.I. as a composite form of individualization -with desirable policy interventions.

Third was a sense that Edgeryders participants' broader social goal has been to open up spaces - physical, virtual, social, political - to fuller participation from a wider citizenry, and, through the diversity which necessarily accompanies such a move, build communities, cities, nations - and individuals - with greater resilience. Many individual life projects described through the online project platform reveal a deeply-rooted commitment to increasing both personal and collective resilience through sharing knowledge and experiences with others. At the heart of this seemed to be a desire to distribute a sense of ownership and responsibility more widely throughout society, such that the relationship between people and institutions is fundamentally reshaped, with institutions becoming more open to diverse and fluid life projects, and thus more dynamic in the ways in which they foster interaction.

It is clear from these themes that, whilst the young people who participate(d) in Edgeryders were prompted to do so as individuals with experiences to share and needs to fulfil, underlying their individual(ized) participation was a collaborative ethos. It is on this basis that we propose the notion of C.I. to describe the reconciliation of individual life projects with the aspiration that these are formulated with and played out alongside others. We began this article by noting that the individualization thesis had, in one sense, advocated for the establishment of communitarian bonds, whilst, in another, portrayed a character seemingly condemned to disconnection. We feel that reflecting upon the activities of Edgeryders participants presents a basis for addressing this inconsistency by revealing how, in their everyday lived realities, young people are embodying the social phenomena that theorists have tended to leave vague and imprecise. Our suggestion is to build on this by conceptualising these modes of cooperation in a more systematic way, in turn shedding light on the (broadly) political stance that these attitudes and experiences necessarily bring with them, and thus denying the purported disinclination amongst youth to involve themselves in the public sphere.

\section{Conclusions}

We conclude this article by stressing that young people have been particularly profoundly affected by the socio-economic insecurity that has beset Europe in recent years. 
In terms of young people's career trajectories, the implications of this are not yet fully apparent, although the need for many to "create what they need" autonomously undoubtedly means that many will be embracing the idea of a 'portfolio' curriculum vitae, whether through choice or obligation. Institutions, particularly public and private sector employers, will need to respond to this emergent phenomenon with open minds, and a degree of trust and creativity of their own. Many of today's youth might not be starting their professional lives with a typical graduate traineeship; they may, however, be using their own resources to build diverse skills bases and global networks which should be no less valuable to an employer seeking dynamic, problem-solving employees or collaborators.

Despite these efforts, and embracing wider issues than work alone, from our analysis of the challenges reported by a diverse group of Edgeryders participants it became apparent that in spite of the institutionalization of the individualization approach, many young people are managing their transition to independent adulthood via explicitly collaborative techniques. Amongst others, these can be identified as: manifesting solidarity through sharing transition experiences, whether positive or negative; (re)creating communities relevant to their own values and needs; demonstrating willingness to sit at the same table with policy makers; presenting and being ready to discuss possible collaborative solutions; asking for (broadly intended) political visibility; putting into practice experiments of coliving and co-working; and showing desire to be engaged - and engage others - in participatory processes.

These kind of actions have rarely been discussed as enacted practices; thus our attempt here has been to propose a systematic inclusion of this nuance in the mainstream theorization of individualization. Although distinctly personal aims, ambitions, experiences and skills still profoundly shape the ways in which young people's pathways towards independent adulthood are navigated, they comprise part of a broader set of aspirations concerned with collaboratively creating a more equal, more sustainable and more resilient global society. It is on this basis that we have proposed the notion of C.I. to describe a mode of life in which the attributes and contributions of the individual are mobilized in conjunction with those of others towards a collective, shared goal. The work areas discussed here show that what we term C.I. articulates the need to fulfil personal needs alongside willingness to collaborate among peers (and even with institutions) and to ultimately propose the enactment of a wider citizenry. 
As we conceive it, C.I. is a more nuanced version of individualization, and therefore a valuable theoretical contribution to youth studies. Further, its conceptualization demands consideration of the impact of collaboration for wider processes of policy making beyond the focus on youth. The Edgeryders experiment of the UnMonastery, for instance, illustrated in section 4.iv, was incorporated into the bid which recently resulted in Matera being named European Capital of Culture 2019, with an estimated profit of 30 million euros for the territory. The starting point for the Edgeryders project was a sense that the policy domain was failing to support European youth at a time of extreme precarity. We contend that by drawing attention to the importance of collaboration within young people's attempts to constructively manage this precarity, public actors and institutions are encouraged to take an equally creative and collaborative approach to the formulation of youth issues.

\section{References}

Aaltonen, Sanna (2013) “'Trying to push things through’: forms and bounds of agency in transitions of school-age young people' Journal of Youth Studies, 16 (3): 375-390.

Bauman, Zygmunt (2001) The Individualised Society. Cambridge: Polity Press.

Beck, Ulrich (1996) Risk Society: Towards a New Modernity, London/Thousand Oaks, CA/New Delhi: Sage.

Beck, U and Beck-Gernsheim, Elisabeth (2002) Individualization: Institutionalised Individualism and its Social and Political Consequences, London: Sage.

Bennett, Andy (1999) 'Subcultures or Neo-Tribes? Rethinking the relationship between Youth Style and Musical Taste’ Sociology 33: 599-617.

Best, Amy (2011) 'Youth identity formation: contemporary identity work' Sociology Compass 5 (10): 908-922.

Biggart, Andy and Walther, Andreas (2005) 'Individualization and the changing youth life’, in Leccardi, Carmen, Ruspini, Elisabetta (eds) (2012) A new Youth? Young People, Generations and Family Life Farnham: Ashgate. 
Castells, Manuel (1996) The Rise of the Network Society, The Information Age: Economy, Society and Culture, Vol. I. Cambridge, MA; Oxford, UK. Blackwell.

Charmaz, Kathy (2006) Constructing Grounded Theory: A practical guide through qualitative analysis, London: Sage.

Chua, Vincent (2013) 'Contextualizing 'networked individualism': The interplay of social categories, role relationships and tasks’ Current Sociology 61 (5-6): 602-625.

Corbin, Juliet and Strauss, Anselm (1990) 'Grounded theory research: Procedures, canons, and evaluative criteria', Qualitative Sociology, 13, 3-21.

Côté, James E. (2002) 'The Role of Identity Capital in the Transition to Adulthood: The Individualization Thesis Examined' Journal of Youth Studies, 5 (2), 117-134.

Della Porta, Donatella and Diani, Mario (2009) Social Movements: An Introduction, Oxford: Blackwell Publishing.

Evans, Karin (2002) 'Taking Control of their Lives? Agency in Young Adult Transitions in England and the New Germany’ Journal of Youth Studies, 5 (3): 245-269.

Furlong, Andy and Kelly, Peter (2005) 'The Brazilianisation of Youth Transitions in Australia and the UK?' Australian Journal of Social Issues (Australian Council of Social Service), 40 (2): 207-225.

Giddens, Antony (1991) Modernity and Self-Identity, Cambridge: Polity Press.

Gordon, Eric and Koo, Gene (2008) 'Placeworlds. Using Virtual Worlds to Foster Civic Engagement’ Space and Culture, 11 (3): 204-221.

Jones, Gill, O’Sullivan, Anne, and Rouse, Julia (2006) 'Young Adults, Partners and Parents: Individual Agency and the Problems of Support', Journal of Youth Studies, 9 (4): 375-392.

Kelly, Peter (2000) 'Youth as an Artefact of Expertise: Problematizing the Practice of Youth Studies in an Age of Uncertainty’ Journal of Youth Studies, 3 (3): 301-315.

Langevang, Thilde and Gough, Katherine (2009) 'Surviving through movement the mobility of urban youth in Ghana' Social and Cultural Geography, 10 (7): 741-756.

Leccardi, Carmen, Ruspini, Elisabetta (eds) (2012) A new Youth? Young People, Generations and Family Life Farnham: Ashgate. 
Marcus, Gaia, and Vickers, Ben, (2012) 'Edgeryders: a network analysis', report to the Council of Europe, published online.

Nugin, Raili (2013) 'Individualism and its different faces: some cases from post-socialist Estonia', Journal of Youth Studies, 16 (7): 809-829.

Pollock, Gary (2002) 'Contingent identities: Updating the transitional discourse’, Young 10(1): 59-72.

Schwartz, Seth J., Cotè, James E., Arnett, Jeffrey (2005) 'Identity and agency in Emerging Adulthood: Two Developmental Routes in the Individualization Process' Youth \& Society, 37 (2): 201-229.

Skelton, Christine (2005) 'The 'self- interested' women academic: a consideration of Beck's model of the individualised individual', British Journal of Sociology of Education, 26 (1): 5-16.

Roberts, Steven (2012) 'One step forward, one step Beck: A contribution to the on-going conceptual debate in youth studies', Journal of Youth Studies, 15 (3): 389-401.

Roberts, Steven (2010) 'Misrepresenting choice biographies?' a reply to Woodman, Journal of Youth Studies, 13(1): 137-149.

Simone, Abdoumaliq (2005) 'Urban circulation and the everyday politics of African urban youth: the case of Douala, Cameroon' International Journal of Urban and Regional Research, 29 (3): 516-532.

Waite, Louise (2009) 'A Place and Space for a Critical Geography of Precarity?' Geography Compass, 3 (1): 412-433.

Walker, Charlie (2009) 'From 'inheritance’ to individualization: disembedding workingclass youth transitions in post-Soviet Russia’ Journal of Youth Studies, 12 (5): 531-545.

Walther, Andreas (2006) 'Regimes of youth transitions’ Young, 14 (2): 119-139.

Webb, Janette (2004) 'Organisations, self-identities and the new economy’ Sociology, 38 (4): 719-738.

Woodman, Dan (2011) 'Class, individualisation and tracing processes of inequality in a changing world: A reply to Steven Roberts’ Journal of Youth Studies, 13: 737-746. 
Woodman, Dan (2009) 'The Mysterious Case of the Pervasive Choice Biography: Ulrich Beck, structure/agency and the middling state of theory in the sociology of youth' Journal of Youth Studies, 12: 243-256.

Wyn, Johanna and Woodman, Dan (2006) 'Generation, Youth and Social Change in Australia’ Journal of Youth Studies, 9 (5): 495-514. 